Sear, R., 2015. Evolutionary Demography: A Darwinian Renaissance in Demography. In: James D. Wright (editor-in-chief), International Encyclopedia of the Social \& Behavioral Sciences, 2nd edition, Vol 8. Oxford: Elsevier. pp. 406-412.

\title{
Evolutionary Demography: A Darwinian renaissance in demography
}

\author{
Rebecca Sear \\ London School of Hygiene and Tropical Medicine \\ Department of Population Health, Keppel Street, London WC1E 7HT \\ Tel: +44 (0)20 72994682 \\ rebecca.sear@1shtm.ac.uk
}

\section{Abstract}

Demography and evolutionary biology have a long history: Darwin was famously influenced by Malthus when developing his ideas on natural selection. The two disciplines remained closely associated throughout the early $20^{\text {th }}$ century. They disassociated after the Second World War, but in recent decades lines of communication between the disciplines have opened again. Initiatives from both evolutionary scientists and demographers have resulted in some genuinely inter-disciplinary work, and evolutionary research is increasingly being published in demography journals and presented at demography conferences. This chapter will briefly survey the history of interaction between the disciplines, and suggest a Darwinian renaissance in demography is underway.

Key words:

evolution, demography, Charles Darwin, Thomas Robert Malthus, Alfred Russell Wallace, evolutionary ecology, fertility, mortality 


\section{Introduction}

Demography is integral to evolutionary biology, given the latter's interest in reproductive success, a composite of survival and reproduction. But evolutionary biology has not always been integral to demography: demography currently considers itself a social science, and few modern demographers have training in biology. This is despite the close association of the two disciplines at their inception. This chapter will outline the relationship between the two disciplines and attempt to demonstrate that, despite something of a separation during the middle decades of the twentieth century, a Darwinian Renaissance is now underway in demography. That a resurgence of interest in evolutionary ideas is seen in demography, more so perhaps than most other social sciences, is no doubt due to a number of factors which ease communication between the two disciplines, including demography's empirical, quantitative basis. But most important is likely to be acknowledgement from both disciplines that the other can be useful in their own endeavours. Many demographers have lamented that demography is a 'discipline without a theory', leading some to turn to evolutionary theory to help fill this gap. Similarly, some evolutionary scientists have recognised the need to engage with the expertise of demographers; some have even argued that "all evolutionary biologists should be demographers" (Metcalf \& Pavard, 2007). Demography has been described as "sex, death and passion wrapped in indicators" (van den Brekel, cited in Coleman 2000) but, when it comes to at least some of the human evolutionary sciences, there has been a tendency to focus too much on the sex and passion without enough emphasis on the indicators - evolutionists could therefore learn much from one of demography's great strengths, which is its focus on high quality data collection and methods, and accurate description before explanatory models are tested.

\section{Darwin, Wallace and Malthus}

Initially, the two fields of evolutionary biology and demography were closely associated. Darwin was famously influenced by one of the earliest writers on population issues,

Thomas Robert Malthus, as he developed his ideas on natural selection - the mechanism of evolution - while writing On the Origin of Species by Means of Natural Selection, or the Preservation of Favoured Races in the Struggle for Life (first published in 1859). Darwin writes in his autobiography (1876):

"In October 1838, that is, fifteen months after I had begun my systematic inquiry, I happened to read for amusement Malthus on Population, and being well prepared to appreciate the struggle for existence which everywhere goes on from long-continued observation of the habits of animals and plants, it at once struck me that under these circumstances favourable variations would tend to be preserved, and unfavourable ones to be destroyed. The results of this would be the formation of a new species. Here, then I had at last got a theory by which to work".

Darwin is referring to Malthus' 1798 work 'An Essay on the Principle of Population', a popular work which expounded Malthus' somewhat pessimistic view that human 
populations had an inevitable tendency to outgrow their resource base, written as a reaction to the Panglossian spirit which prevailed at the time that human society had never had it better. Malthus, in contrast to this optimism, believed that human society was doomed to perpetual misery because of the disparity between the rate of increase of human populations and that of their food resources. Given, he argued, that food production can only grow, at best, arithmetically $(2+2+2 \ldots)$ but that human population can grow geometrically $(2+4+16+32 \ldots)$ then human populations will inevitably grow faster than food production, leading to a never-ending cycle of rapid population growth being brought back into line with resources by the 'positive checks' of famine, war and disease:

"The power of population is so superior to the power of the earth to produce subsistence for man, that premature death must in some shape or other visit the human race. The vices of mankind ${ }^{l}$ are active and able ministers of depopulation. They are the precursors in the great army of destruction, and often finish the dreadful work themselves. But should they fail in this war of extermination, sickly seasons, epidemics, pestilence, and plague advance in terrific array, and sweep off their thousands and tens of thousands. Should success be still incomplete, gigantic inevitable famine stalks in the rear, and with one mighty blow levels the population with the food of the world"

Malthus' purple prose undoubtedly had a part to play in the popularity of his essay, which was so well received that it was reprinted in six editions, one of which Darwin came across several decades after the first edition. Alfred Russell Wallace, too, read Malthus, and was equally stimulated by his arguments about the carrying capacity of environments. From Wallace's acceptance speech on receiving the Darwin-Wallace Medal in 1908:

"Finally, both Darwin and myself, at the critical period when our minds were freshly stored with a considerable body of personal observation and reflection bearing upon the problem to be solved, had our attention directed to the system of positive checks as expounded by Malthus in his 'Principles of Population.' The effect of this was analogous to that of friction upon the specially-prepared match, producing that flash of insight which led us immediately to the simple but universal law of the "survival of the fittest," as the long-sought effective cause of the continuous modification and adaptation of living things."

Curiously, both Darwin and Malthus practiced what they preached in their own reproductive lives. Malthus, to foreshadow the discipline of demography to come, took a policy-oriented view and recommended that the dangers of unchecked population growth should be restrained through the mechanisms of late marriage and sexual abstinence (the title of the $2^{\text {nd }}$ edition of his essay was 'An Essay on the Principle of Population': or a View of its Past and Present Effects on Human Happiness; with an enquiry into our

${ }^{1}$ these 'vices of mankind' are contraception and abortion, of which Malthus, as a clergyman, strongly disapproved 
Prospects respecting the Future Removal or Mitigation of the Evils which it occasions' demonstrating clearly both his interests in the practical applications of his work and a penchant for even longer book titles than Darwin). Malthus only had 3 children himself and has no living descendants today. Darwin, proponent of the individual-level perspective that natural selection preserves those 'favoured' in the struggle for life, had 10 children and now has more than a hundred currently living descendants (Wallace, more moderately, had 3 children and now has a handful of living descendants).

\section{Evolutionary biology and demography in the early $20^{\text {th }}$ century}

Evolutionary biology and demography continued to develop in close association throughout the early $20^{\text {th }}$ century. Prominent figures during this period moved freely between these disciplines. Alfred Lotka, for example, a mathematician well known in evolutionary biology for his models of population biology (the Euler-Lotka and LotkaVolterra equations are still widely used), also served as an officer of both the Population Association of America (PAA) and the International Union for the Scientific Study of Population Problems (IUSSPP, which later dropped the second P to become the IUSSP, now the largest international population organisation). Raymond Pearl, a biologist who also worked on population problems, was involved in founding the biology journals Quarterly Review of Biology and Human Biology but also the demography associations $P A A$ and IUSSPP. He is perhaps most well known for some demographic work, particularly that on mortality and longevity, demonstrating in the 1920s, for example, an association between moderate alcohol consumption and long life.

Practitioners of both disciplines were also closely associated in the eugenics movement, aimed at encouraging the reproduction of those deemed to have desirable attributes and discouraging those deemed undesirable, which reached its peak during this period. Eugenics was promoted by some biologists who saw 'social Darwinism' as an obvious extension of Darwin's theories of evolution and a way to improve the human species (and was devised, incidentally, by Darwin's cousin, Francis Galton). Many prominent population activists, such as the pioneers of the birth control movement in the US and UK respectively, Margaret Sanger and Marie Stopes, were also proponents of eugenics. Stopes was such an ardent eugenicist she supposedly cut her son out of her will when he married a short-sighted woman, arguing that his children may inherit the defect of myopia (Connolly 2008). In the UK, the Eugenics Society was involved in the foundation of the Population Investigation Committee, a charity still based at the London School of Economics, which publishes one of the major, and eminently respectable, demographic journals, Population Studies.

\section{Divergence after the Second World War}

The two disciplines diverged after the Second World War, however. The eugenics movement may have been partly responsible for this cleavage. The post-war backlash against eugenics resulting from the explicitly eugenicist aims of Nazi Germany, as well as other human rights abuses linked to the eugenics movement, led to the social sciences striving hard to dissociate themselves from the linkage of biological theories to human 
affairs. In subsequent decades, the social sciences largely (and often vehemently) denied any role for biology in human behavior, and biologists themselves steered clear of engaging with the social sciences. Demography became firmly situated within the social, and not the biological, sciences. In the US today, for example, demography units are often situated within sociology departments. As a result of this divergence, many demographers have been raised in a social science tradition which views biological explanations of any human behavior with considerable wariness. As the demographer Richard Udry (1999) puts it: "Our shared disciplinary [social science] immune systems recognize biological explanation of behavior as an infection, and reject it."

The reasons for this re-positioning may not have been entirely political, however. The rapid demographic changes which took place during the $20^{\text {th }}$ century led many to the conclusion that demography must be more influenced by social factors than biology, since genetic change could not take place so rapidly. An additional factor may have been the very applied nature of demography in the post-WWII period. Much demographic data collection and analysis is focused on describing mortality and fertility levels and their determinants, so that policy could be directed at reducing mortality and fertility rates where they were still high. Arguably, such applied science, at least in the early stages of mortality and fertility reduction, has relatively little need of theory, as substantial success can be achieved in, for example, reducing child mortality rates in low income countries, in the absence of any overarching theoretical framework.

Whatever the reasons for the divergence of demography and biology, demography has now effectively shaken off the spectre of eugenics, which biology has still not succeeded in doing. This is perhaps a little unfair given that demography was involved quite explicitly in promoting population control in the decades after WWII in the interests of curbing global population growth, in some cases at least with aims which skirted dangerously close to eugenics (see Matthew Connolly's 2008 history of the population control movement "Fatal Misconception", which was reviewed by journalist Fred Pearce as "... an investigative narrative of how individuals, NGOs, governments and UN agencies colluded over decades to sideline the human rights of hundreds of millions of the world's poorest citizens" New Scientist, 24/05/08). Those applying an evolutionary perspective to human behaviour in recent decades have in contrast taken care to emphasise the errors in eugenicist science and have been much less keen to engage in policy. Demography has since had its own debates about the controversial population control movement (the well-respected demography journal Population and Development Review published three highly critical book review of Fatal Misconception, including one by prominent demographer and recent president of the IUSSP John Cleland), and now population policies typically have an explicit human rights, rather than population control, agenda, but it is still perhaps ironic that the social science community tends to regard demography as a respectable social science whereas the application of evolutionary biology to human behaviour is not yet wholly accepted as a reputable endeavour.

\section{Renaissance}


This post-war split led to several decades of non-fraternisation between demography and evolutionary biology, but the rapprochement of the disciplines does now seem to be well underway. After a period of biologists' relative lack of interest in the social sciences, the 1970s saw the emergence of sociobiology - the application of evolutionary theory to social behaviour - which stemmed from the work of (non-human) animal ethologists in the 50s and 60s (Segerstralle 2001). E.O.Wilson controversially applied this approach to human behaviour in the final chapter of his textbook on Sociobiology: the New Synthesis (published in 1975). Despite the protests of many within the social science community that this would inevitably lead to a second round of eugenics, the application of evolutionary theory to the human sciences has developed into a thriving and diverse field. While evolutionary psychologists have perhaps become numerically the most dominant of the evolutionary social scientists, there is also a successful discipline of evolutionary anthropology, as well as the integration of evolutionary theory into many other aspects of the human sciences, such as a movement to establish a field of evolutionary medicine.

The resurgence in enthusiasm for combining demography and evolutionary ideas began in the 1980s with a number of meetings aimed at bringing together biologists and demographers. Initially, the focus was on mortality, with workshops on 'Population \& biology' in 1981, 'Upper limits to human life span' in 1987, 'Convergent issues in genetics and demography' in 1988, 'Biodemography of longevity' in 1991, 'Life span: evolutionary, ecological and demographic perspectives' in 2001, though there was also a workshop on 'Biodemography of fertility and family behaviour' in 2002. These workshops have resulted in some exciting advances being made in evolutionary demography during the last few decades, as well as the increasing appearance of evolutionary ideas at population conferences. All the major population conferences, including the IUSSP, PAA, European Association for Population Studies, and the British Society for Population Studies have now held sessions explicitly devoted to evolutionary demography. Short courses to train students in evolutionary demography have been held at the International School for Demography in Rostock, Germany and at Stanford University. Labs in evolutionary demography, led by the Evolutionary Biodemography lab at The Max Planck Institute for Demographic Research in Rostock, Germany are beginning to appear in the US and Europe. What may be the first tenure-track position in human evolutionary demography was advertised in 2010 at Yale. Finally, and perhaps most notably, an Evolutionary Demography Society ${ }^{2}$ was established in 2013, which held its first conference in October 2013.

\section{Quantifying the Darwinian Renaissance in demography?}

As both are empirical disciplines, demographers and evolutionary biologists presumably require empirical evidence that a Darwinan renaissance may be underway. In order to provide some very crude evidence, I have attempted to determine whether biological terms may be increasing in frequency demography journals over time. To do this, I analysed the number of times the terms 'evolutionary', 'biology' and 'darwin*' appeared in three top demography journals (Demography, Population Studies and Population \&

\footnotetext{
${ }^{2}$ http://www.evodemos.org/default.htm
} 
Development Review) over the last few decades, using the jstor database. This database allows a count of the number of times a word appears in these journals within a certain time range (I restricted the analysis to search the full text of research articles only). The number of articles (and therefore total number of words) published has also increased considerably in these journals over this time period, so to control for this I constructed a faux 'rate' for the appearance of each of these terms by dividing the number of times the term of interest was mentioned by the number of times the word 'population' appeared: making the assumption that the relative frequency of the term 'population' would have remained constant over time. For comparison, I performed the same calculations for the social science terms 'anthropology' and 'psychology'.

Figure 1 shows the absolute increase in the 'rate' of use for each term by decade in the jstor database (Population Studies appears in jstor since 1947, Demography since 1964 and PDR since 1975; the analysis was only possible up to 2010 since the jstor database does not include the most recent issues of journals). This figure shows the frequency of all terms has increased relative to the term population over this time period, indicating that demography is becoming more diverse in the disciplines it interacts with. But there are differences in how frequently the different terms are mentioned, and how rapidly these rates have increased over time. 'Biology' is the most widely used term overall, perhaps suggesting that biology and demography have always been somewhat linked, and has increased substantially over time. 'Evolutionary' has seen a much larger increase over time, however. Initially it was seen very infrequently in these journals, but showed the largest increase over time to become as common as the social science terms included. 'Anthropology' has steadily increased over time, perhaps reflecting the emergence of the field of anthropological demography. 'Psychology' showed little increase until the last decade, which may correspond to a relative lack of interest from demographers in psychology until very recently - perhaps suggesting the emergence of a very new field of psychological demography?

\section{Why did the renaissance occur?}

The reasons for this Darwinian Renaissance are undoubtedly many. The similarity in subject matter of evolutionary biology and demography - resulting from both fields being interested in fertility and mortality - is clearly very important. As the most biological of the social sciences, demography is likely to be rather more open to biological thinking than other social sciences. Demography is also a strongly empirical and largely quantitative discipline, and has not, therefore, been diverted into the cul-de-sac of postmodernism as have so many of the other social sciences. The demographer David Coleman (2000) goes as far to say: "Demography without numbers is a bland form of social or historical waffle". Developments in genetics and physiology mean that it is increasingly straightforward to link the demographic processes of birth and death with biomarkers and genetic factors, which may have concentrated some demographers' minds on the importance of such biological factors: Kreager (2008) suggests that "the tremendous development of genetics has recalled demographers' attention to evolutionary theory as an inescapable element of modern population thought." 
But perhaps one of the most important factors for demographic interest in incorporating biological theories is that, unlike some of the other social sciences, it is not wedded to any particular theory. In fact, it has been a recurrent complaint from within the field itself that demography is a discipline without a theory ${ }^{3}$ (which makes it somewhat ironic perhaps, that Darwin declared Malthus had "given him a theory by which to work": see quote from his autobiography above). As early as 1952, Vance asked during his PAA presidential address "Is theory for demographers?" A number of prominent demographers, including Livi-Bacci, have described the discipline as "a technique rather than a science" (Livi-Bacci 1984); and a plenary at EAPS in 1995 by Guillaume Wunsch was titled " 'God has chosen to give the easy problems to the physicists' Or: Why demographers need theory". This lack has left a void, which has become particularly noticeable as demographers have become increasingly interested in individual-, rather than population-, level processes, and in causal explanations for demographic phenomena: Hobcraft (2006) called for demographers "to tackle the difficult and interesting problems of understanding behaviour, rather than undertaking elaborate description", an endeavour which really requires theory. Demography has, in fact, not been shy to borrow from other disciplines in the past: economic thinking has been particularly influential in demographic models of the fertility transition, for example (the shift from high to low fertility which began in Europe in the $18^{\text {th }}$ century and has now occurred almost worldwide). To quote David Coleman (2000) again: demography has long been "a space where other specialists come for a while to do some of their work".

Finally, important in the reunifying of demography and biology is the commitment of individual researchers to work together to solve particular problems. Two of the most prominent scientists who have worked hard to reunite the two disciplines are Jim Vaupel and Jim Carey. A social and natural scientist respectively, they have been instrumental in organising and developing many of the workshops, courses, and the new society mentioned above. They argue that a significant factor in the progress of evolutionary demography has been the identification of particular problems that both disciplines can contribute to:

"The good intentions of top scientists are not enough to integrate two fields with fundamentally different disciplinary histories, professional cultures, and epistemological frameworks. To make progress it is imperative to layout a clear set of important (and ultimately fundable) questions that lie at the disciplinary interface. This is particularly important for integrating disciplines with disparate

\footnotetext{
${ }^{3}$ It should be noted that this is not a universally held view among demographers: for example, in Micklin and Poston's (2005) brief survey of the theoretical basis of demography they cites Gutman (1960), who argues that demography does offer 'illuminating theoretical statements'. Your view of whether demography is theory-free or not to some extent depends on your definition of theory: Burch (2003) argues that if a theory is redefined as a model, defined in turn as an approximation of reality, rather than a set of laws from which testable hypotheses can be generated, then demography is rich in theory, because it is rich in such models
} 
historical roots, such as demography with its roots in the social and analytical sciences and biology with its roots in the natural and experimental sciences."

Carey and Vaupel 2005

\section{The incorporation of evolutionary biology into demography}

Carey and Vaupel (2005) argue that the first few seminars described above were not particularly successful, and did not produce much in the way of outputs, because a suitable problem had not yet been identified. In more recent years, evolutionary demography has really begun to take off, after the discipline began to make significant progress in the study of aging and mortality rates at old ages. A recognition by demographers that standard demographic models failed to accurately describe the pattern of mortality at very old ages, as average longevity increased in developed nations, led to the active forging of links with the biological sciences in the hope that evolutionary models may prove useful. Models which take account of how natural selection has shaped mortality trajectories are now being used to help explain the demographic puzzle of why mortality rates should begin to plateau or decline at old ages (when standard demographic models predict increasing mortality rates with increasing age). A particularly notable feature of this work is its comparative nature - evolutionary demography is not just for humans, but this field has produced considerable research on how mortality trajectories vary across non-human species (throughout the natural world) and even on inanimate objects: this work has demonstrated remarkable variability in the shape of age-specific mortality trajectories across species, suggesting that both demography and evolutionary theories on aging need to be rethought (Vaupel et al 1998; Jones et al 2014). This area has also benefitted from the attention that demographer Ron Lee (2003) has given to intergenerational transfers in the aging process. Lee has used evolutionary theory to develop models of aging which incorporate intergenerational transfers as a key component influencing mortality rates, which also dovetails nicely with work in the evolutionary sciences emphasising the importance of such transfers in our species (Hrdy 2009).

Work on mortality may be the most significant success story for evolutionary demography so far, but evolutionary thinking is beginning to inform other areas of demography too. In the field of reproduction, David Coleman (2000) has highlighted areas of fertility research which require biological input, for example, to explain the puzzle of why people continue to have children even when they bring only material disadvantage and when effective contraception is readily available. Such behaviour is not explicable using standard demographic, typically economic, models of fertility, and can really only be explained with recourse to evolutionary arguments - children don't appear to make one healthy, wealthy or happy, but we do descend from ancestors who had physiological and behavioural adaptations which resulted in reproduction: any individual without such physiological abilities or behavioural tendencies towards childbearing did not become an ancestor. Empirical work by demographers developing an interest in the evolutionary demography of reproduction have tended to focus on genetic influences on reproduction. For example, early publications stemming from the collaboration of demographer Hans-Peter Kohler with psychologist Joseph Rodgers used twin study 
designs to ask "is fertility behaviour is in our genes?" (Kohler et al 1999; this collaboration also resulted in the publication of an edited volume one the Biodemography of Reproduction, 2003). The answer was: partially, yes. More recently, Melinda Mills has been making use of technological advances in genetics and is using GWAS (genomewide-association-search: Mills et al 2013) to explore the genetic basis to fertility behaviour; again, finding evidence that genes do matter.

Evolutionary demography is having an impact on demography not just in terms of publications but also the kinds of data that are collected through the large-scale surveys demographers typically use. Studies investigating biosocial influences on demographic events are only possible if data on the potential biological and social influences on demography exist. Demographic surveys have always collected detailed socio-economic information, but are increasingly collected detailed biological information too. John Hobcraft, for example, is a demographer who has been influential in promoting the inclusion of biomarkers in longitudinal surveys, so that it is easier to "elaborate pathways from biology through the brain/mind to behaviors and outcomes, particularly for social, demographic, economic, and health domains." (Hobcraft 2009).

I'll end this section with another quote from Carey \& Vaupel (2005), who have argued that incorporating more biology may be essential if demography is to remain an active and important discipline:

“..every discipline including demography is faced with the perennial struggle to define and renew itself and to ensure its relevance in an ever changing world. Like other social sciences, demography is slowly coming to terms with important truths that the biological sciences have provide beyond any doubt: that all aspects of humans - mind, behaviour, body-are products of biological evolution. It follows that this program, in particular, and biological demography in general, should help demography maintain a robust, energetic and creative presence in modern science." Carey \& Vaupel 2005

\section{What evolutionists can learn from demographers}

"Nothing in biology, the eminent biologist Theodosius Dobzhansky (1900-1975) asserted, makes sense except in the light of evolution. It is equally valid to say that nothing in evolution can be understood except in the light of demography" Carey \& Vaupel 2005, p84

The section above has described work done largely by demographers becoming interesting in using evolutionary theory to inform their work, but enthusiasm for the reemergence of evolutionary biology comes from both disciplines: prominent evolutionary anthropologists such as Kaplan and Borgerhoff Mulder have also engaged explicitly with the demographic community. They have formed links with demographers, not just publishing in demographic journals and organising sessions on evolutionary demography at population conferences, but also by setting up working groups such as the IUSSP Panel 
for Evolutionary Perspectives on Demography (active 2004-2010, and resulting in the publication of two special journal issues).

Evolutionists bringing a more demographic perspective into their work have tended to focus largely on reproduction (unlike demographers bringing evolution into their work). Kaplan and colleagues, for example, have written influential papers on theories of fertility, both theoretical and empirical, drawing on the demographic literature but incorporating elements of life history theory (the evolutionary framework relevant for studying demography), such as parental investment, and also giving a historical perspective on reproductive behaviour over time (Kaplan 1996; Kaplan \& Lancaster 2003). Kaplan has also helped moved forward debates in demography, by directly setting up tests of alternative hypotheses, where social and evolutionary explanations of fertility behaviour were in conflict (though frequently evolutionary and social science explanations are not in conflict with one another, because they explain the same phenomena at different levels: Sear under review). For example, he empirically contrasted two models of intergenerational resource flows, which have been used in theories of the demographic transition. The influential demographer, Jack Caldwell's 'wealth flows' hypothesis for the demographic transition argues that in pre-demographic transition societies, net wealth flow is up generations, from parents to children. Evolutionary theory, on the other hand, predicts that net wealth flow will always be downwards, from parents to children: wealth is always used in the service of reproduction, never the reverse. Kaplan (1994) tested these alternate models by measuring the economic costs and benefits of children in hunter-gatherer societies. His findings suggested that children were always a net economic cost to their parents, even in traditional subsistence societies (which doesn't mean that changes in the costs and benefits of children were not factors in the demographic transition, nor that children never provide benefits to their parents, just that this one assumption of the wealth flows hypothesis was not supported).

The benefits of such cross-fertilisation for the evolutionary community include borrowing from the methodological sophistication of demography, not just in formal demography but also statistical analysis of demographic data and large-scale, longitudinal datasets. Kim Hill and Magdalena Hurtado produced one of the earliest monographs in evolutionary ecology which made heavy use of statistical techniques and advances in demography (such as the use of event history models for demographic events). Their book Ache Life History: the Ecology and Demography of a Foraging People (Hill \& Hurtado 1993) was an impressive tour de force testing a wide range of hypotheses derived from life history theory using their longitudinal dataset on the Ache, South American hunter-gatherers, and was very influential in shaping the developmental of the field of human evolutionary ecology (the study of physiology and behaviour in ecological context, within the framework of evolutionary theory). Other evolutionary ecologists have followed in their footsteps, interested in testing hypotheses on demographic data deriving from evolutionary theory but making use of the methods developed to analyse human demographic data. Increasingly, evolutionary ecologists are also making use of large-scale datasets collected by demographers, seeing an opportunity to test their 
hypotheses on existing large, rich datasets, rather than relying on small-scale data collection in 'traditional' populations (Nettle et al 2013).

\section{Remaining differences of opinion}

This should not be taken to mean that the discipline of evolutionary demography is entirely uncontroversial, nor that all demographers are comfortable with the idea that biology matters. In some quarters at least there still may be the view that 'biological' and 'social' explanations are alternates so that when trying to explain any human behaviour "'biology' and the 'social' are locked in an explanatory zero-sum game in which any ground ceded to the former diminishes the value of the latter" (Carey \& Vaupel 2005). On the other side of the fence, some evolutionists have yet to fully engage with demographers to improve their understanding and analysis of the demographic phenomena they are interested in. There are also still conceptual differences between the two disciplines in that demography is a 'bottom-up' science, which starts with an empirical observation and subsequently attempts to explain that phenomena (such as why does fertility decline?); whereas evolutionary biology is a 'top-down' science, which sees data as a means to an end to test hypotheses which derive from an overarching theoretical framework (Kaplan \& Gurven 2008). This primary interest in data versus theory means that the two disciplines will always have distinct and separate goals, but there is still sufficient overlap between the disciplines for the increasing interaction between the two to be scientifically fruitful.

\section{Conclusion}

Of all of the social sciences and humanities, demography seems perhaps to be one of those disciplines where a Darwinian renaissance is genuinely underway. Kreager, for example, wrote in 2009 that "evolutionary biology, of course, re-emerged in the 1990s as a potential source of evidence and theoretical insight into central demographic problems" (emphasis added). This is partly because renaissance is the right term to apply in the case of demography, given the close association of the two disciplines in their early development. But also because there is evidence of an emerging discipline of evolutionary demography, driven by both evolutionary scientists and demographers recognizing the need to draw on each other's expertise. Indeed, this discipline has not just emerged but is sufficiently well established to be "com[ing] of age" and "entering its adolescence" in the words of one author who contributed to a special issue on biodemography in the demography journal Demographic Research (Wachter 2008). I'll leave the last word to the demographer and biologist who have perhaps done the most to establish this discipline

"Although still a modest subfield within demography, biodemography may be one of the fastest growing areas of demography and one of the most innovative and stimulating"

Carey \& Vaupel 2005 


\section{References and further reading}

Burch, T.K. (2003) Demography in a new key: a theory of population theory. Demographic Research 9(11): 263-284

Carey, J. R., \& Vaupel, J. W. (2005). Biodemography. In D. L. Poston \& M. Micklin (Eds.), Handbook of Population (pp. 625-658). New York: Kluwer Academic Press.

Coleman, D. (2000). Demography in Intellectual Context: a subject in search of a home. The Position of Demography among other Disciplines. Z. Pavlik. Prague, Dept of Demography and Geodemography, Charles University: 27-35, and other chapters in this volume on 'The Position of Demography among other Disciplines'

Hill, K., \& Hurtado, A. M. (1996) Ache Life History: The Ecology and Demography of a Foraging People. New York: Aldine de Gruyter.

Hobcraft, J. (2006). The ABC of demographic behaviour: How the interplays of alleles, brains, and contexts over the life course should shape research aimed at understanding population processes. Population Studies 60(2): 153-187.

Hobcraft, J. (2009). Reflections on the incorporation of biomeasures into longitudinal social surveys: an international perspective. Biodemography and Social Biology 55(2): 252-69.

Hrdy, S. B. (2009) Mothers and Others: The Evolutionary Origins of Mutual Understanding. Cambridge, Massachusetts: Belknap Press.

Jones, O. R., A. Scheuerlein, et al. (2014). Diversity of ageing across the tree of life. Nature 505(7482): 169-173.

Kaplan, H. (1994). Evolutionary and wealth flows theories of fertility: empirical tests and new models. Population and Development Review 20(4): 753-791.

Kaplan, H. (1996). A theory of fertility and parental investment in traditional and modern human societies. Yearbook of Physical Anthropology 39: 91-135.

Kaplan, H. and J. Lancaster (2003). An evolutionary and ecological analysis of human fertility, mating patterns and parental investment. Offspring: Human Fertility in Biodemographic Perspective. K. W. Wachter and R. A. Bulatao. Washington, National Academies Press: 170-223.

Kaplan, H. and M. Gurven (2008). Top-down and bottom-up research in biodemography. Demographic Research 19(44): 1587-1602

Kohler, H.-P., Rodgers, J. L., \& Christensen, K. (1999). Is fertility behavior in our genes? Findings from a Danish twin study. Population and Development Review, 25(2), 253-288.

Kreager, P. (2009). Darwin and Lotka: two concepts of population. Demographic Research 21(16): 469-502.

Lee, R. D. (2003). Rethinking the evolutionary theory of aging: Transfers, not births, shape social species. Proceedings of the National Academy of Sciences of the United States of America 100(16): 9637-9642.

Livi-Bacci, M. (1984) A Concise History of World Population. Wiley.

Metcalf, C. J. E. and S. Pavard (2007). Why evolutionary biologists should be demographers. Trends in Ecology \& Evolution 22(4): 205-212. 
Micklin, M. and D. L. Poston (2005). Prologue: The demographer's kin: 50 years of growth and change. Handbook of Population. D. L. Poston and M. Micklin. New York, Kluwer Academic/Plenum Publishers: 1-15.

Mills (2013) A meta GWAS (genetic wide association search) of fertility tempo and quantum. Paper presented at the International Union for the Scientific Study of Population conference, Busan, Korea http://www.iussp.org/sites/default/files/event_call_for_papers/GWAS_IUSSP201 3_Final_0.pdf

Rodgers, J. L., \& Kohler, H. P. 2003 The Biodemography of Human Reproduction and Fertility. Boston: Kluwer Academic Publishers. New York, Kluwer Academic/Plenum Publishers

Segerstralle, U. (2001) Defenders of the Truth: the Sociobiology Debate. Oxford University Press.

Udry, R. (1999) How to alienate your natural allies and attract your enemies. Behavioural and Brain Sciences 22: 911

Vaupel, J. W., Carey, J. R., Christensen, K., Johnson, T. E., Yashin, A. I., Holm, N. V., . . . Curtsinger, J. W. 1998. Biodemographic trajectories of longevity. Science 280(5365): 855-860.

Wachter, K. W. 2008. Biodemography comes of age. Demographic Research 19(40): 1501-1512.

Wunsch, G. 1995. God has chosen to give the easy problems to the physicists, or why demographers need theory. Plenary given at European Population Conference, Milan. http://www.un.org/popin/confcon/milan/plen6.html

Book review symposium published in Population \& Development Review, 2008, vol 34(3): reviews of Connelly's Fatal Misconception by Malcolm Potts, John Cleland, Dennis Hodgson 
Figure 1: Frequency of terms in three demography journals over time

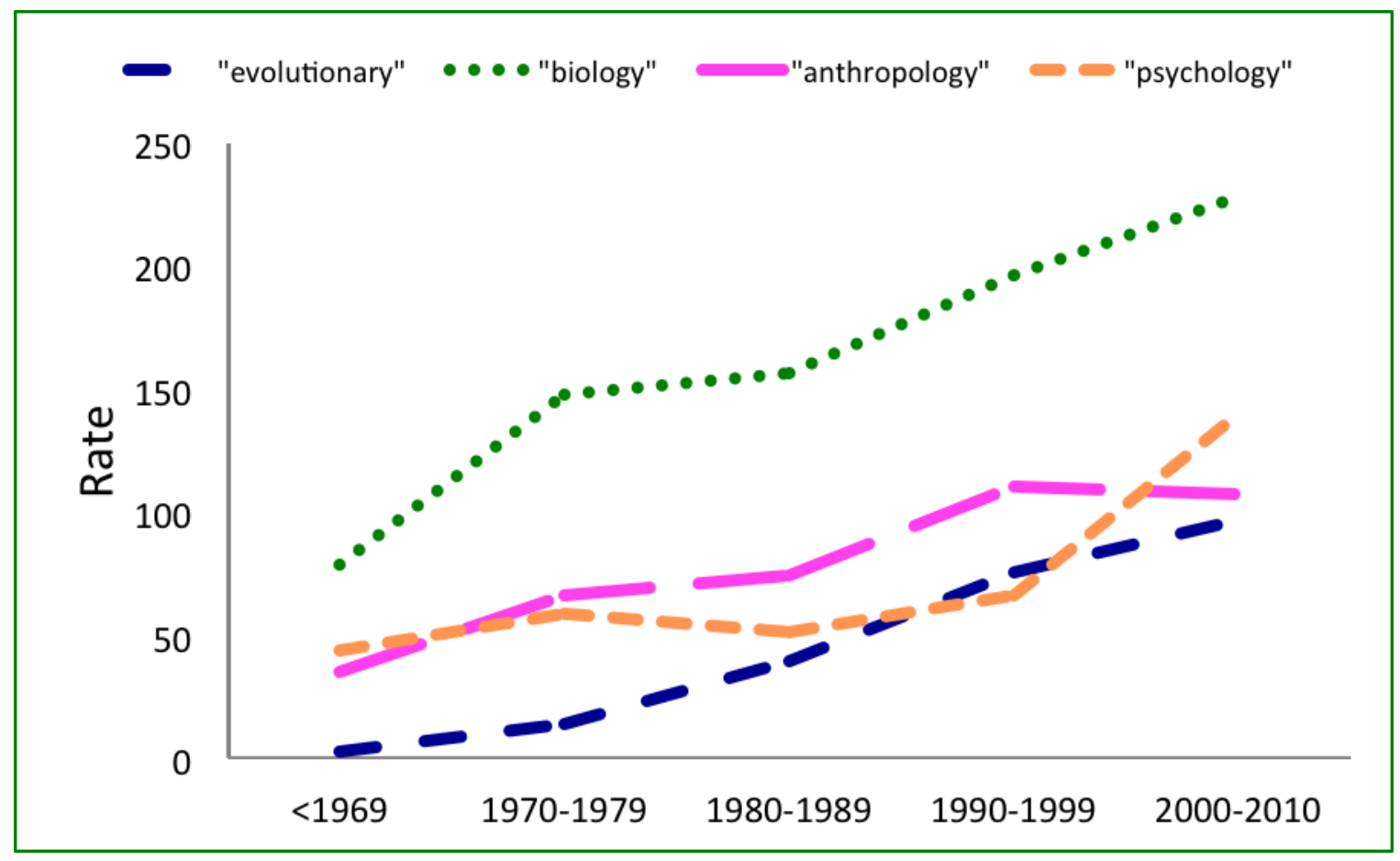

